\title{
Microsporidial Infections in Immunodeficient and Immunocompetent Patients
}

\author{
Rainer Weber and Ralph T. Bryan
}

\begin{abstract}
From the Divisisn of Infectoms Diseases. Department of Medicine. University Hospital. Zurich. Switzerland; and the National C'nter for Infectious Diseases. Conters for Disease Control and Preventon. Atlanta.
\end{abstract}

Gorgia. LSA

\begin{abstract}
Microsporidia are obligate, intracellular, spore-forming protozoal parasites. Their host range is extensive and includes most invertebrates and all classes of vertebrates. Five microsporidial genera (Enterocytozoon, Encephalitozoon, Septata, Pleistophora, and Nosema) and unclassified microsporidia have been associated with human disease, which appears to manifest primarily in immunocompromised persons. The clinical manifestations of microsporidiosis are diverse and include intestinal, pulmonary, ocular, muscular, and renal disease. The majority of microsporidial infections in persons infected with human immunodeficiency virus (HIV) are attributed to Enterocytozoon bieneusi, an important cause of chronic diarrhea and wasting. Four cases of microsporidial infection among persons not infected with HIV who had documented or presumed cellular immunodeficiency and four cases of corneal stroma infection due to microsporidia in immunocompetent patients have been described. Furthermore, the first case of traveler's diarrhea due to $E$. bieneusi in an immunocompetent and otherwise healthy patient is reported in this issue. The sources of human microsporidial infections and modes of transmission are unknown.
\end{abstract}

Many microorganisms were first identified or gained attention as human pathogens when they were isolated from immunocompromised persons, particularly those infected with the human immunodeficiency virus (HIV). Increased awareness of such organisms has often been facilitated by the development of improved diagnostic techniques. The identification of new pathogens in immunocompromised populations often leads to the recognition that these agents may also cause disease in immunocompetent persons. In this issue. Sandfort and colleagues report what they believe is the first case of intestinal microsporidial infection due to Enteroc vtozoon bienetsi in an immunocompetent, HIV-seronegative patient with acute, self-limited traveler's diarrhea [1]. The microsporidial species $E$. bieneusi was first identified (by transmission electron microscopy) in the case of a patient with AIDS and diarrhea in 1985 [2] and has subsequently been recognized as a frequent etiologic agent of chronic diarrhea associated with HIV infection [3, 4].

\section{The Organisms}

The nontaxonomic term microsporidia, proposed in 1882 by Balbiani [5], relates to a group of organisms belonging to the phylum Microspora, of the subkingdom Protozoa. Microsporidia are small unicellular parasites that are considered

Received 28 February 1994.

Reprints or correspondence: Dr. Rainer Weber. Division of Infectious Diseases, Department of Medicine, University Hospital. CH-8091 Zurich, Switzerland.

Clinical Infectious Diseases 1994;19:517-21

(C) 1994 by The University of Chicago. All rights reserved

1058-4838/94/1903-0017\$02.00 true eukaryotes because they have a nucleus with a nuclear envelope, because they have an intracytoplasmic membrane system, and because their chromosomes are separated on mitotic spindles. Because microsporidia also exhibit certain prokaryotic features (prokaryote-like ribosomal RNA and absence of mitochondria. peroxisomes. and Golgi membranes), they are considered phylogenetically to be ancient protozoa [6]. Microsporidia are obligate intracellular parasites and have no metabolically active stages outside the host cell. A unique life cycle involving a proliferative merogonic stage followed by a sporogonic stage results in distinctive and resistant infective spores. Mature spores contain an exceptional tubular extrusion apparatus for injecting infective sporular contents into the host cell [7].

Microsporidia have long been recognized as a cause of disease in various animal groups and are one of the most prevalent groups of parasites. with an extensive distribution that includes most invertebrates and all classes of vertebrates [8]. Since 1857. when Nägeli first described newly identitied parasites in silkworms [9], more than 100 microsporidial genera and almost 1,000 species have now been identified [10].

The first human case of reasonably well-documented microsporidial infection was reported in 1959 [11]. To date. five genera (Enterocytozoon. Encephalitozonn. Septata. Pleistophora, and Nosema), in addition to some as yet unclassified microsporidia, have been associated with human disease. which appears to predominantly affect immunocompromised persons. Only a few cases have been described among persons not infected with HIV. Microsporndia have gained increasing attention as important opportunistic pathogens in the evolving pandemic of HIV infection. and over 400 cases of HIV-associated microsporidial infection have been docu- 
mented. The potential sources and means of transmission of human microsporidial infections are uncertain $[3,4,7,8$, 12].

The taxonomy of microsporidia is complex and is changing rapidly under the scrutiny of molecular taxonomists. At present, the taxonomic classification of microsporidia that infect humans and other mammals is not conclusive, and consensus is lacking about the exact number and names of families and orders and the classification of genera within families [7]. Until recently, Sprague's classification system, proposed in 1977 and updated in 1982, was the most widely used $[7,8]$. Taxonomic criteria have primarily been based on ultrastructural features, the configuration of the nuclei in spores and in the developmental stages, the host-parasite interface, and the number of coils of the tubular extrusion apparatus. Species characteristics also included host-cell specificity and patterns of organ, tissue, and cell involvement with the parasite. In 1992. Sprague and colleagues proposed a comprehensive revision in which differences in chromosome cycles were treated as the most fundamental taxonomic characteristics [10]. The authors commented that they deliberately avoided the subject of evolutionary relationships because present knowledge is based on a limited number of molecular studies. Nevertheless, recent data derived from antigenic and molecular analysis of some microsporidial organisms suggest that ultrastructural examination of microsporidia may not be appropriate for defining relationships of genera and for differentiating species within a genus [7]. Therefore, current classification systems will likely be amended significantly when results of comprehensive molecular analyses become available.

\section{Mechanism of Pathogenicity}

A long-term evolutionary host-parasite interaction has resulted in generally low pathogenicity of microsporidia in most mammalian hosts, which usually manifests as latent or mildly symptomatic infection. In mammalian Encephalitozoon cuniculi infection, the parasites are able to persist in their hosts despite an active immune response. Latent infection remains asymptomatic as long as a balance between multiplication of parasites and host immune response is maintained [8]. Acute, potentially fatal encephalitozoonosis has been observed in some neonatal mammals, particularly when they have been infected transplacentally [8].

Microsporidial infection activates antibody production; however, antibodies alone do not appear to yield protection. The role of a competent cellular immune response in suppressing microsporidial multiplication has been established experimentally $[13,14]$. In manifest encephalitozoonosis in animals, the inflammatory reaction is typically an intense diffuse cellular infiltration or granulomatous lesion characterized by infiltrations of mononuclear cells including lymphocytes, plasma cells, and macrophages, often around a necrotic center. These lesions may persist after the disappearance of the organisms themselves [8].

No animal model exists for infection due to the species $E$. bieneusi. Current data on humans suggest that patients with severe cellular immunodeficiency are at highest risk for developing microsporidial disease. It is not understood, however, whether microsporidial infection in these patients is primarily a reactivation of latent infection acquired before immunosuppression occurs or whether microsporidial disease is caused by recently acquired infection. In immunodeficient patients, inflammatory reaction in tissue infected with microsporidia is often minimal or even absent. The pathophysiology of human microsporidial infection is not sufficiently understood $[3,4,7]$.

\section{Microsporidiosis in HIV-Infected Patients}

E. hieneusi, which has thus far been detected only in humans, accounts for the majority of recognized microsporidial infections in HIV-infected persons. Another microsporidial species, Septata intestinalis, has recently been described as a cause of intestinal and disseminated infection in a small number of HIV-infected persons [15, 16]. Cases of HIV-associated encephalitozoonosis due to Encephalitozoon hellem [17], and possibly E. cuniculi, are being recognized with increasing frequency. The spectrum of recognized Encephalitozoon-associated disease in patients with AIDS appears to be expanding and now includes keratoconjunctivitis, sinusitis, bronchiolitis, nephritis, ureteritis, cystitis, hepatitis, and peritonitis. [3. 4, 12, 17-23]. A single case of pleistophora myositis in a patient with AIDS has also recently been reported [24].

E. hieneusi has frequently been determined to be the cause of chronic diarrhea and/or biliary illness in severely immunodeficient HIV-infected patients, particularly those with $\mathrm{CD}^{+}$cell counts of $<50-100 / \mathrm{mm}^{3}$ who have otherwise unexplained chronic diarrhea [25-31]. Results of endoscopic studies on patients with AIDS and chronic diarrhea, which show prevalences of E. bieneusi that range from $7 \%$ to $50 \%$, may represent overestimation of the organism's occurrence because of the selection bias often inherent in such studies. Nevertheless, ongoing prospective studies of HIV-associated chronic diarrhea indicate a substantial prevalence $(9 \%-16 \%)$ of $E$. bieneusi in patient groups who are evaluated using coprodiagnostic techniques to detect microsporidia $[3,4,12$, 28, 29]. E. bieneusi may also cause self-limited diarrhea in HIV-infected persons, particularly when cellular immunodeficiency is less severe [30]. Up to one-third of patients with intestinal microsporidiosis are coinfected with other intestinal pathogens; these coinfections may occur simultaneously or sequentially. When coinfection is present, the pathogenic role of the etiologic agent may be difficult to assess. However, the majority of epidemiologic and clinical 
studies show a strong correlation between the presence of microsporidia and diarrheal disease $[25,26,28-31]$.

Some investigators have questioned the causal association between microsporidial infections and diarrhea. In a casecontrol study in which intestinal biopsy results for $55 \mathrm{HIV}$ infected patients who had chronic diarrhea were compared with those for 51 HIV-infected patients who did not have diarrhea, the investigators found no significant difference in the occurrence of microsporidial infection in the two patient groups [32]. However, these findings will require further evaluation because of the inadequate sample size of the study and other possible methodical limitations. Some ongoing studies of HIV-infected patients suggest the possibility of asymptomatic enteric carriage of microsporidia preceding wasting and/or diarrheal illness [30].

\section{Diagnosis of Infection}

Diagnosis of microsporidiosis currently depends on morphological demonstration of the organisms themselves. Serological tests for detection of antibodies to Encephalitozoon have been developed, but available results suggest that these tests may not be feasible for diagnosis of human infection. particularly in immunodeficient patients [33]. Progress is being made with respect to in vitro propagation of microsporidia [34], which is crucial for developing immunofluorescence and serological assays as well as for testing the effectiveness of antimicrosporidial drugs. Molecular probes are also being developed but are currently not available outside research laboratories.

Detection of microsporidial parasites has often been based on electron microscopic examination of tissue specimens because of the organisms' small size and staining properties. which may hamper visualization of the spores and developing stages of the organism when routine staining techniques are used. The small spores (the stages at which microsporidia usually are identified) range in size from 1 to $2.5 \mu \mathrm{m}$ for most species found in humans. With use of special staining techniques, initial detection of microsporidia by light microscopic examination of tissue sections and of more readily obtainable specimens such as stool, duodenal aspirates, urine, sputum, nasal discharge, bronchoalveolar lavage lluid, and conjunctival smears is now becoming routine practice $[3,4,12,21,31,35,36]$. Definitive identification of species is made with use of a specific fluorescein-tagged antibody (immunofluorescence) technique or electron microscopy [3. 4. 12].

A recently developed coprodiagnostic technique based on chromotrope staining has been helpful in the diagnosis of intestinal microsporidiosis in HIV-infected patients [31], and -as reported in this issue by Sandfort and colleagues-also appears to be useful in screening of stool specimens from immunocompetent persons [1]. Chemofluorescent optical brightening agents also stain microsporidial spores, but stain- ing may not be specific [28]. Small fungal organisms may be present in fecal specimens. and these organisms as well as other fecal elements may also be brightened: brightened microsporidial spores are not characterized by a specific morphology [28].

\section{Treatment of Microsporidiosis}

Experience in therapy for microsporidiosis in immunodeficient patients is limited. and blinded. placebo-controlled trials have not been performed. Preliminary observations of the possible utility of albendazole for infections duc to $S$ intestinalis and Encephatitozon species have been reported [37. 38]. In contrast. the success of therapy for intestinal $l:$ : bieneusi infection has been limited. Preliminary reports of a good clinical response among patients treated with metronidazole [26] could not be confirmed. In addition. treatment with various other antibiotics or antiprolopoal drugs has been attempted without success. Recent reports have suggested that in some cases treatment with alhendazole mals lead to abatement of diarrhea and weight gain even though parasites are still present in hiopsy specimens of the small intestine and microsporidial spores are still detected in stowl specimens sbtained after treatment $\{39,40\}$

\section{Microsporidiosis in Patients Not Infected with HIV}

Of patients not infected with HIV, four with systemic microsporidial infection and decumented or presumed cellular immunodeficiency due to causes other than AIISS have been described so far. These patients include a child with systemic encephalitozoon infection and cellular immunodeficiencr of unknown etiology [41]: an athymic child with wystemic nosema infection [42]; an adult male with myontis due to Pleitrophora species who had severe cellular immunodeficiencs but remained HIV-seronegative during a t-vear follow-up [43. 44]: and a child with systemic encephaliwooon infection who may have had impaired immune response. as indicated by cutaneous ancrgy to tuberculin antigen after vaccination with BC 'G (bacille Calmette-Guérin) |111. In addition. four immunocompetent and otherwise healthy patients with corneal stroma infection have been described $[4,-49]$. The cornea may be considered an "immunoprivileged" site because local immune response to infection in the cirnea mav be less intense than systemic response.

Some authors have speculated that micruporidial species such as $E$. bichensi may be "natural" human parasites that possibly cause transient diarrhea but normally remain belou the threshold of detection or clinical mantestation. as has been observed with regard to other opportunistic protozoa in patients with AIDS [50]. Indeed. preliminary reports have indicated that microsporidial species first identified in patients with AIDS will not be confined to the patient group. Intestinal E. hiencusi infection has been reported in six of 
593 African children with diarrhea and two of 397 children without diarrhea who lived in an area with a low prevalence of HIV, but the HIV serostatus of these children was not determined [51]. Available epidemiologic data, however, are too limited to suggest that residence or travel in tropical countries increases one's risk for microsporidial infection. The human infections that have been reported are globally dispersed and have been documented in persons from all continents except Antarctica [3, 4, 12].

In conclusion, the case of the immunocompetent patient with traveler's diarrhea due to E. bieneusi presented by Sandfort et al. in this issue adds to our increasing knowledge of the epidemiology of human microsporidial infections and suggests that clinicians who evaluate patients with diarrheal illness that is potentially travel-related should now consider intestinal microsporidiosis in their differential diagnoses.

\section{References}

1. Sandfort J, Hannemann A. Gelderblom H, Stark K, Owen RL, Ruf B. Encrocyozoon biencusi infection in an immunocompetent patient who had acute diarrica and who was not infected with the human immunodeficiency virus. Clin Infect Dis 1994;19:514-6.

2. Desportes I. Le Charpentier Y, Galian A, et al. Occurrence of a new microsporidan: Enteroc yozoon bicheusi n.g., n.sp., in the enterocytes of a human patient with AIDS, J Protozool 1985;32:250-4.

3. Bryan RT. Microsporidia. In: Mandell GL. Bennett JE. Dolan R. eds. Principles and practice of infectious diseases. 4th ed. New York: Churchill Livingstone, 1994 (in press).

4. Weber R, Bryan RT. Schwartz DA. Owen RL. Human microsporidjal infections. Clin Microbiol Rev 1994 (in press).

5. Balbiani M. Sur les microsporidies ou psorospermies des articules. Comptes rendus hebdomadaires des séances de l'Academie des sciences (Paris) 1882;95:1168-71

6. Vossbrinck CR, Maddux JV, Friedman S, Debrunner-Vossbrinck BA, Woese CR. Ribosomal RNA sequence suggests microsporidia are extremely ancient eukaryotes. Nature 1987:326:411-4.

7. Canning EU. Microsporidia. In: Krejer JP. Baker JR, eds. Parasitic protozoa. 2nd ed. Vol 6. New York: Academic Press, 1993.

8. Canning EU, Lom J, Dykova I. The microsporidia of vertebrates. New York: Academic Press. 1986.

9. Nägeli KW. Über die neue Krankheit der Seidenraupe und verwandte Organismen. Botanische Zcitung 1857:15:760-I.

10. Sprague V. Becnel JJ. Hazard El. Taxonomy of phylum microspora. Crit Rev Microbiol 1992: 18:285-395.

11. Matsubayashi H, Koike T, Mikata T. Hagiwara S. A case of Encephalitozoon-like body infection in man. Arch Pathol 1959:67:181-7.

12. Bryan RT, Weber R. Microsporidia: emerging pathogens in immunodeficient persons [editorial]. Arch Pathol Lab Med 1993; 117:1243-5.

13. Schmidt EC. Shadduck JA. Murine encephalitozoonosis model for studying the host-parasite relationship of a chronic infection. Infect Immun 1983;40:936-42.

14. Schmidt EC. Shadduck JA. Mechanisms of resistance to the intracellular protozoan Encephatitozon cuniculi in mice. J Immunol 1984; 133:2712-9.

15. Cali A, Kotler DP, Orenstein JM. Septata intestinalis N.G.. N.Sp., an intestinal microsporidian associated with chronic diarrhea and dissemination in AIDS patients. J Protozool 1993;40: 101-12.

16. Orenstein JM. Dieterich DT. Kotler DP. Systemic dissemination by a newly recognized intestinal microsporidia species in AIDS. AIDS 1992:6:1 143-50.
17. Didier ES, Didier PJ, Friedberg DN, et al. Isolation and characterization of a new human microsporidian, Encephalitozoon hellem (n.sp.), from three AIDS patients with keratoconjunctivitis. J Infect Dis 1991:163:617-21.

18. Schwartz DA, Bryan RT, Hewan-L.owe KO, et al. Disseminated microsporidiosis (Encephalitozoon hellem) and acquired immunodeficiency syndrome. Autopsy evidence for respiratory acquisition. Arch Pathol Lab Med 1992; 116:660-8.

19. Schwartz DA. Visvesvara GS, Diesenhouse MC, et al. Ocular pathology of microsporidiosis: role of immunofluorescent antibody for diagnosis of Encephalitozon hellem in biopsies, smears, and intact globes from seven AIDS patients. Am J Opththalmol 1993; 1 15:285-92.

20. Schwartz DA. Visvesvara GS, Leitch GJ, et al. Pathology of symptomatic microsporidial (Encephalitozoon hellem) bronchiolitis in the acquired immunodeficiency syndrome: a new respiratory pathogen diagnosed from lung biopsy, bronchoalveolar lavage, sputum, and tissue culture. Hum Pathol 1993;24:937-43.

21. Weber R, Kuster H, Visvesvara GS, Bryan RT, Schwartz DA, Lüthy R. Disseminated microsporidiosis due to Encephalitozoon hellen: pulmonary colonization, microhematuria, and mild conjunctivitis in a patient with AIDS. Clin Infect Dis 1993: 17:415-9.

22. Terada S, Reddy KR, Jeffers LJ, Cali A, Schiff ER. Microsporidian hepatitis in the acquired immunodeficiency syndrome. Ann Intern Med 1987; 107:61-2.

23. Zender HO, Arrigoni E. Eckert J, Kapanci Y, A case of Encephalitozoon cuniculi peritonitis in a patient with AIDS. Am J Clin Pathol 1989;92:352-6.

24. Chupp GL. Alroy J, Adelman LS. Breen JC, Skolnik PR. Myositis due to Pleistophora (microsporidia) in a patient in AIDS. Clin Infect Dis 1993: 16:15-21.

25. Orenstein JM. Chiang J, Steinberg W, Smith PD, Rotterdam H, Kotler DP. Intestinal microsporidiosis as a cause of diarrhea in human immunodeficiency virus-infected patients: A report of 20 cases. Hum Pathol 1990;21:475-81.

26. Eeftinck Schattenkerk JK, van Gool T, van Ketel RJ, et al. Clinical significance of small-intestinal microsporidiosis in HIV-I-infected individuals. Lancet 1991;337:895-8.

27. Pol S, Romana CA, Richard S, et al. Microsporidia infection in patients with the human immunodeficiency virus and unexplained cholangitis. N Engl J Med 1993; 328:95-9.

28. van Gool T, Snijders F, Reiss P. et al. Diagnosis of intestinal and disseminated microsporidial infections in patients with HIV by a new rapid fluorescence technique. J Clin Pathol 1993;46:694-9.

29. Weber R, Vugia DJ, Juranek DD, et al. Prospective evaluation of diarrhea and enteric parasitosis in HIV/AIDS [abstract no 1527]. In: Program and abstracts of the 32nd Interscience Conference on Antimicrobial Agents and Chemotherapy (Anaheim, CA). Washington, DC: American Society for Microbiology, 1992.

30. Weber R, Bryan T, Vugia DJ, Kaiser L, Sauer B, Lüthy R. Clinical manifestations and course of intestinal Enterocytozoon bieneusi microsporidiosis [abstract WS-B|4-5]. In: Program and abstracts of the 9th International Conference on AIDS (Berlin). 1993.

31. Weber R, Bryan RT, Owen RL, Wilcox CM, Gorelkin L, Visvesvara GS. Improved light-microscopical detection of microsporidia spores in stool and duodenal aspirates. N Engl J Med 1992:326:161-6.

32. Rabeneck L, Gyorkey F, Genta RM. Gyorkey P. Foote LW. Risser JM. The role of Microsporidia in the pathogenesis of HIV-related chronic diarrhea. Ann Intern Med 1993; 119:895-9.

33. Didier ES, Shadduck JA, Didier PJ, Millichamp N, Vossbrinck CR. Studies on ocular microsporidia. J Protozool 1991;38:635-8.

34. Visvesvara GS, Leitch GJ, Gorelkin L, Wilcox M. Weber R, Bryan RT. Short-term in vitro culture of Enterocyozoon bienensi from four different patients with AIDS [abstract PO-B10-1447]. In: Program and 
abstracts of the 9 th International Conference on AIIDS (Berlin). 1993.

35. Field A, Hing M, Milliken S, Marriott D. Microsporidia in the small intestine of HIV-infected patients: a new diagnostic technique and a new species. Med J Aust 1993; 158:390-4.

36. Weber R, Kuster H. Keller R. et al. Pulmonary and intestinal microsporidiosis in a patient with the acquired immunodeficiency syndrome. Am Rev Respir Dis 1992:146:1603-5.

37. Orenstein JM, Dieterich DT, Kotler DP. Albendazole as a treatment for disseminated microsporidiosis due to Septata imestinalis in AIDS patients. In: Program and abstracts of the Workshop on Intestinal Microsporidia in HIV Infection (Paris). Paris: INSERM. 1992.

38. Weber R. Sauer B. Spycher MA. et al. Detection of Septata intestinatis in stool specimens and coprodiagnostic monitoring of successful treatment with albendazole. Clin Infect Dis 1994; 19:342-5.

39. Dieterich DT, Lew EA, Kotler DP, Poles MA, Orenstein JM. Treatment with albendazole for intestinal disease due to Enterocrorom bienlusi in patients with AIDS. J Infect Dis 1994:169:178-83.

40. Blanshard C. Ellis DS. Tovey DG. Dowell S, Gazzard BG. Treatment of intestinal microsporidiosis with albendazole in patients with AIDS. AIDS 1992:6:311-3.

41. Bergquist NR. Stintzing G. Smedman L. Waller T. Andersson T. Diagnosis of encephalitozoonosis in man by serological tests. Br Med J 1984:288:902.

42. Margileth AM, Strano AJ, Chandra R, Neufie R, Blum M, McCully
RM. Disseminated nosematosis in an immunologically compromised infant. Arch Pathol 1973;95:145-50.

43. Ledford DK, Overman MD. Gonzalvo A. Cali A. Mester W. Lockev RF. Microsporidiosis myositis in a patient with acquired immunodeficiency syndrome. Ann Intern Med 1985; 102:628-30.

44. Macher AM, Neafie R. Angritl P. Tuur SM. Microsporidial myositis and the acquired immunodeficiency syndrome (AIDS): a four-year follow-up [letter]. Ann Intern Med 1988; 109:343

45. Ashton N. Wirasinha PA. Encephalitozoonosis (nosematosis) of the cornea. Br J Ophthalmol 1973;57:669-74.

46. Pinnolis M. Egbert PR. Font RL. Winter FC . Nosematosis of the cornea. Arch Ophthalmol 1981:99:1044-7.

47. Davis RM. Font RL. Keisler MS. Shadduck JA. Corneal microsporidiosis. A case report including ultrastructural observatons Ophthalmology 1990:97:953-7.

48. Shadduck JA, Meccoli RA. Davis R, Font RL. First isolation of a microsporidian from a human patient. J Infect Dis 1990:162:773-6.

49. Cali A. Meister IJM. Lowder CY, el al. Corneal microsporidioses: char acterization and identification. J Protozool 1991:38:215S-7S.

50. Canning EU, Hollister WS. Human infections with microsporidia. Reviews in Medical Microbiology 1992;3:35-42.

51. Bretagne S. Foulet F. Alkassoum W. Fleury I. Develoux M. Prevalence of microsporidia spores in stools from children in Niamey. Niger. In: Program and abstracts of the Workshop on Intestinal Microsporidia in HIV Infection (Paris). Paris: INSERM. 1992. 